\author{
Research Article
}

\title{
Effects of Melicope ptelifolia Aqueous Extract on Sperm Parameters and Testosterone Level in Sprague-Dawley Rats
}

\author{
Nazizarini Binti Mohd Najib, Enoch Kumar Perimal, Mohd. Roslan Bin Sulaiman, Ahmad Akira Omar \\ Farouk and Tengku Azam Shah Bin Tengku Mohamad*
}

Department of Biomedical Science, Faculty of Medicine and Health Sciences, Universiti Putra Malaysia, 43400 Serdang, Selangor Darul Ehsan, Malaysia.

\begin{abstract}
The increasing number of prevalence infertility cases is becoming a major public health problem in developing countries due to changes in diet and lifestyle. Melicope ptelefolia (M.ptelifolia) is known for its health benefit as a sex enhancing effect among the Malays folk however there is no clinical data to prove it until these days. The main aim of the present study is to identify the effects of Melicope ptelifolia Aqueous extract (MPAE) on Sperm Parameters and Testosterone Level . A total of 30 male Sprague Dawley rats were divided equally into five different groups. MPAE was given by orally gavage for 28 days at a dose of $100 \mathrm{mg} / \mathrm{kg}, 200 \mathrm{mg} / \mathrm{kg}$ and $500 \mathrm{mg} / \mathrm{kg}$ body weight to the animals of group II ( $n=6)$, III ( $n=6)$ and IV (n=6), respectively. The animals of group I (control, $n=6)$ had distilled water and group V had sildenafil citrate. Sperm Parameters were carried include sperm count, motility, mobility and morphology together with serum testosterone level for Testosterone level result. Results were analyzed using one way ANOVA test followed by Tukey test and the data were considered significant at $\mathrm{p}<0.05$. Oral administration of MPAE extract showed an increased sperm count and sperm viability. Oral administration of the MPAE resulted a significant increased $(\mathrm{p}<0.05)$ for Group II, III and IV in sperm count and sperm morphology. A significant increased increased was recorded for Group I, II, III and IV in sperm viability. However, sperm vitality remained normal in all the groups. From our present experimental finding we are tempted to suggest that the MPAE could be a potential male fertility agent.
\end{abstract}

Keywords: Melicope ptelifolia, Sperm Parameters, Testosterone, Fertility

1.0

\section{Introduction}

M.ptelefolia is one of the medicinal plant resources which have a great potential to be marketed worldwide (Karim et.al., 2011). M.ptelifolia is a shrub and known as "tenggek burung, pauh-pauh, medang beberas, cabang tiga, tapak itik by the local while the Javanese people called it sampan and Siamese called it as Uam, Sam Ngam (Shoji et al., 1989). M.ptelefolia Champ Ex. Benth (Rutaceae), locally known as "tenggek burung," is one of the most common medicinal herbs that can be easily found in Peninsular Malaysia and also in several other Asian countries (David, 1955).

Previous findings reported M.ptelifolia had a slightly bitter taste, crunchy young leaves, pungent, and lemon-lime aroma. Its physical characteristic is said trifoliate, green, thick, broad leaves and has small white and greenish flowers. M.ptelifolia grows wildly in open area, shrub edge, paddy field and turf areas of land and also grows well in peat and sulphate acid soil. The main spreader for this plant are birds. M.ptelifolia is an easy plant to grow and do not need intensive care (Karim et.al., 2011).

In it pharmacology report, M.ptelifolia extract are reported to possess antimicrobial and cytotoxic properties, as well as being rich in antioxidants (Abas et.al., 2006; Rasadah \& Zakaria, 1988). Previous phytochemical studies on the plant revealed the presence of 2,2dimethyl-2H-1-benzopyrans, benzopyrans dimmers, and bisisoquinoline alkaloids as major constituents [Kamperdick et.al., 1997; Kamperdick et.al., 1999; Van et.al., 1998). In Malaysia, the plant variety have reported to contain O-geranylcoumaric acid, furoquinoline alkaloids, and several polyprenylated acetophenones including 2,4,6- trihydroxygernylacetophenone (tHGA) (Abas et.al., 2010 ; Shaari et.al., 2006).

M.ptelifolia had been used for various medical purposes including the treatment of inflammation and infection by the locals in Malaysia (Dahlan \& Rosli, 2015). Various parts of the M.ptelifolia have been used traditionally for centuries as natural remedy for fever, stomach ache, rheumatism and the treatment of wounds and itches (Karim et.al., 2011)). Apart from being one of the most popular traditional fresh vegetables among the Malays of Malaysian community, different parts of M.ptelefolia has been used traditionally for centuries as natural remedy for fever, emmenagogue, stomach ache, and rheumatism as well as treatment of wounds and itches. In addition there have been many other usages of the herb, for example, to prevent premature ejaculation, as an aphrodisiac, and for its blood pressure lowering effects (Loi, 1977; Perry \& Metzger, 1980). Present study was therefore undertaken to identify whether the MPAE shows any beneficial effects on sperm count, sperm viability and the rate of spermatogenesis.

* Correspondence: Department of Biomedical Science, Faculty of Medicine and Health Sciences, Universiti Putra Malaysia, 43400 Serdang, Selangor, Malaysia. e-Mail: $\underline{\text { azamshah@upm.edu.my }}$

(C) 2018 by the Author(s). Life Sciences, Medicine and Biomedicine (ISSN: 2600-7207) Published by Biome Journals. Wholly owned by Biome Scientia Sdn Bhd., previously by WWH Networks Sdn Bhd. Attribution-ShareAlike 4.0 International (CC BY-SA 4.0). This open access article is distributed based on the terms and conditions of the Creative Commons Attribution license https://creativecommons.org/licenses/by-sa/4.0/ 
The fresh leaves of $M$. ptelefolia were collected from Serdang area. The plant material then identified and authenticated by a resident botanist through comparison with herbarium specimens of MP (SK153/02) kept at the Mini Herbarium, Institute of Bioscience, Universiti Putra Malaysia (UPM). Firstly, the freshly collected leaves of MP were wash in tap water and oven dried $\left(\sim 25^{\circ} \mathrm{C}\right)$ for $5-7$ days. The dried plant were grounded to a fine powder using grinder and stored at $-20^{\circ} \mathrm{C}$ until used. Next, the dried plant powder of $200 \mathrm{~g}$ were extracted by heated in distilled water $(1 \mathrm{~L})$ for $30 \mathrm{~min}$. The extract was filtered with Whatman No. 1 filter paper and resulting filtrate was freeze dried. Freeze dried material was reconstituted separately in distilled water to give the required doses for each experiment. Resulting water extract was filtered through a tea strainer. Filtrate was dried in a freeze dryer and stored at $4^{\circ} \mathrm{C}$ in amber glass vials until use.

\subsection{Animal experimentation}

Sprague-Dawley male rats at about 8 to 12 weeks old, weighing approximately $250-350 \mathrm{~g}$ were used in this study. The SpragueDawley rats undergo 12-hour light/dark cycle at the animal house of Faculty of Medicine and Health Sciences, Universiti Putra Malaysia for 1 week prior to the experiment with access to food and water ad libitum. The rats were habituated to the experiment room condition for at least 1 day before the experiment. The experiment were conducted in accordance with current guidelines for the care of laboratory animals as well as the ethical guidelines for investigations of anti-arthritic activity in conscious and non-conscious animals, approved by the Ethical Committee, Faculty of Medicine and Health Sciences, Universiti Putra Malaysia (UPM/IACUC/AUP-R041/2017).

\subsection{Sample collections}

Animals were sacrificed by overdose of ketamine and xylaxine mixture 24 hrs following the treatment schedule.

\section{Evaluation of sperm parameters}

The test for Sperm Parameter Test was carried out as described by Raidah \& Mahanem, (2015). On day 29, the animals were fasted overnight and killed $24 \mathrm{~h}$ after the last treatment using an overdose of ketamine and xylaxine mixture. Sperm count, motility or progression, viability and morphology were determined according to the WHO criteria (WHO 2010).

\section{$2.5 \quad$ Serum testosterone level}

Blood samples were collected directly from all groups by using cardiac puncture for estimation of serum testosterone level. Serum testosterone level was sent to Clinicpath for further analysis. Serum testosterone level analysis was conducted in Pathology Lab, Clinicpath Bukit Jalil.

\subsection{Statistical analysis}

All data were subjected to a one-way analysis of variance (ANOVA), followed by Tukey test to determine the level of significance between control and the treated groups. A difference was considered significant at $p<0.05$. Data are reported here as mean \pm standard deviation $( \pm \mathrm{SD})$.

\subsection{Results and Discussion}

Oral administration of the MPAE resulted a significant increased $(\mathrm{p}<0.05)$ for Group II, III and IV in sperm count and sperm morphology. A significant increased increased was recorded for Group I, II, III and IV in sperm viability. However, sperm vitality remained normal in all the groups.

Table 1.1: Effect of MPAE on Sperm count of the male rats

\begin{tabular}{llc}
\hline Groups & Description & Sperm Count $(\mathbf{x 1 0} 7$ cell $/ \mathbf{m l})$ \\
\hline I & Distilled Water & $7.55 \pm 0.12$ \\
II & $100 \mathrm{mg} / \mathrm{kg}$ & $7.75 \pm 0.11$ \\
III & $200 \mathrm{mg} / \mathrm{kg}$ & $8.17 \pm 0.10^{*}$ \\
IV & $500 \mathrm{mg} / \mathrm{kg}$ & $8.37 \pm 0.10^{*}$ \\
V & Sildenafil Citrate & $8.91 \pm 0.08^{*}$ \\
\hline
\end{tabular}

Each column represents the mean \pm S.E.M. of 6 rats.

* Significantly different at $\mathrm{p}<0.05$.

Table 1.1 shows the sperm count for group I, II, III, IV and V of the Sprague-Dawley male rats after consuming certain doses of MPAE (for treated group), distilled water (for negative control group) and sildenafil citrate (for positive control group). Group IV (at $8.91 \pm$ $0.08)$ displayed the highest mean sperm count followed by Group IV $(8.37 \pm 0.10)$, Group III $(8.17 \pm 0.10)$, Group II (7.75 \pm 0.11$)$ and the lowest, Group I $(7.55 \pm 0.12)$. The increased in sperm count indicates the effect of MPAE on testicular spermatogenesis. Testiscular histology studies are underway to verify this conclusion. 
Table 1.2: Effect of MPAE on Sperm Motility of the male rats

\begin{tabular}{llccc}
\hline Groups & Description & Progressive & Non-Progressive & Immotile \\
\hline I & Distilled Water & $0.49 \pm 0.01$ & $0.15 \pm 0.01$ & $0.36 \pm 0.01$ \\
II & $100 \mathrm{mg} / \mathrm{kg}$ & $0.51 \pm 0.03$ & $0.11 \pm 0.00$ & $0.38 \pm 0.03$ \\
III & $200 \mathrm{mg} / \mathrm{kg}$ & $0.52 \pm 0.02$ & $0.10 \pm 0.02$ & $0.38 \pm 0.04$ \\
IV & $500 \mathrm{mg} / \mathrm{kg}$ & $0.50 \pm 0.01$ & $0.10 \pm 0.02$ & $0.40 \pm 0.02$ \\
V & Sildenafil Citrate & $0.52 \pm 0.02$ & $0.09 \pm 0.02$ & $0.39 \pm 0.03$ \\
\hline \multicolumn{4}{r}{}
\end{tabular}

Sperm Motility revealed that male rats from MPAE treated showed a higher percentage of progressive sperms however no significant differences recorded. The increase in grade sperm motility with MPAE suggests that MPAE affects sperm maturation process in epididymis. The body weight of the control and treated animal did not show significant changes throughout the course of the investigation (data not shown).

Table 1.3: Effect of MPAE on Sperm viability of the male rats.

\begin{tabular}{llc}
\hline Groups & Description & Sperm Viability (\%) \\
\hline I & Distilled Water & $0.78 \pm 0.01$ \\
II & $100 \mathrm{mg} / \mathrm{kg}$ & $0.80 \pm 0.01 *$ \\
III & $200 \mathrm{mg} / \mathrm{kg}$ & $0.83 \pm 0.00 *$ \\
IV & $500 \mathrm{mg} / \mathrm{kg}$ & $0.83 \pm 0.01 *$ \\
V & SildenafilCitrate & $0.83 \pm 0.01 *$ \\
\hline & Each column represents the mean \pm S.E.M. of 6 rats.
\end{tabular}

Sperm viability was also increased with MPAE. For example, at lower dose Group 1 (distilled water) the viability was $0.78 \% \pm 0.01$, Group II $(100 \mathrm{mg} / \mathrm{kg})$, the viability was $0.80 \% \pm 0.01$, Group III $(200 \mathrm{mg} / \mathrm{kg})$, Group IV $(500 \mathrm{mg} / \mathrm{kg})$ and Group IV (sildenafil citrate), the viability was $0.83 \% \pm 0.01$.

Table 1.4: Sperm Morphology for Groups I, II, III, IV and V.

\begin{tabular}{llc}
\hline Groups & Description & Normal Sperm Morphology $(\%)(\mathbf{x 1 0} 7 \mathbf{c e l l} / \mathbf{m l})$ \\
\hline I & Distilled Water & $0.80 \pm 0.01$ \\
II & $100 \mathrm{mg} / \mathrm{kg}$ & $0.85 \pm 0.01$ \\
III & $200 \mathrm{mg} / \mathrm{kg}$ & $0.89 \pm 0.00 *$ \\
IV & $500 \mathrm{mg} / \mathrm{kg}$ & $0.93 \pm 0.01 *$ \\
V & Sildenafil Citrate & $0.92 \pm 0.01 *$ \\
\hline \multicolumn{2}{c}{$*$ significantly different at p.E.M. of 6 rats. } \\
& \multicolumn{2}{c}{ Each column represents the mean \pm S.E. }
\end{tabular}

Similarly, to the sperm count parameter, results in the sperm morphology showed significant increase for Group II, III and IV. Group IV (at $0.93 \pm 0.01)$ displayed the highest Normal Sperm Morphology $(\%)(\mathrm{x} 107 \mathrm{cell} / \mathrm{ml})$ followed by Group V $(0.92 \pm 0.01)$, Group III $(0.89$ $\pm 0.00)$, Group II $(0.85 \pm 0.01)$ and lowest by Group I $(0.80 \pm 0.01)$. The result indicated that MPAE treatment was able to maintain normal morphology of sperm as any sperm deformities were associated with functional deficiencies. This caused reduced motility and fertilization ability. Besides that, morphological sperm parameters were important for fertilization step meanwhile DNA integrity were crucial as it was related with the establishment and continuation of pregnancy (Tomlison et al., 2001). Apart from that, sperm morphology is the most informative semen measurement for discriminating between fertile and infertile male.

This study was conducted to assess the effect of MPAE on sperm characteristic in adult male Sprague Dawley rats for 28 days by comparing different dosages of MPAE $(100 \mathrm{mg} / \mathrm{kg}, 200 \mathrm{mg} / \mathrm{kg}$ and $500 \mathrm{mg} / \mathrm{kg})$ and distilled water as negative control.

Some andrological parameter was used including sperm count, viability, motility and morphology in order to monitor the fertility of rats. The mean sperm count in rats treated with different dosage $(100 \mathrm{mg} / \mathrm{kg}, 200 \mathrm{mg} / \mathrm{kg}$ and $500 \mathrm{mg} / \mathrm{kg}$ ) showed significant difference when compared to negative control group. One possibility for this effect is due to increase in hormones such as FSH, LH or testosterone which tend to increase sperm count (Jana et al., 2006). LH and FSH are essential for quantitatively normal spermatogenesis in pubertal rats (Kulin and Reither, 1973). The increase of LH and FSH are consequent rising in testosterone production, which may therefore be held responsible for spermatogenesis process in rat treated with MPAE. Moreover, MP exhibit anti-oxidant properties (Abas et al., 2006). Trans et. al., 2005 reported that antioxidants could increase sperm output in healthy rats. Generally, anti-oxidant reduces cell wide oxidative damage, support redox balance 
within leydig cells, release leydig cells from oxidative inhibition of testosterone synthesis and the rate of testosterone secretion (Glade et al., 2015). Therefore, by reducing oxidative stress, it can safely increase the testosterone status.

In sperm count, the methods such as counting chambers, computed assisted sperm analysis system (CASA) and automated system such as IVOS HTMIDENT; HTM integrated Visual Optical System semen analyzer were commonly used (Krause and Viethen., 1999). Computer-Aided Sperm Analysis (CASA) systems are the evolution of multiple photomicrography exposure and video- micrography techniques for spermatozoa track, using computer equipped with Imaging software. A CASA system refers to the physical equipment used to visualize and digitalize static and dynamic sperm images and to the methods used to process and analyze them (Boyer et.al., 1989).

Sperm motility is an important parameter to evaluate sperm quality and fertilizing potential (Mangelsdorf et al., 2003). Furthermore, it was clear that spermatozoa which were highly motile will have a greater opportunity of fertilization. This present study showed that the total mean percentage of motile sperms was significant for group IV and V compared to the negative control. A correlation between mitochondrial activities and motile sperm has been shown by using flow cytometry (Auger et al., 1993). Hung et al., (2008) demonstrated that ATP from mitochondrial sources did contribute to sperm motility in rhesus monkey sperm. Moreover, the study also found a close and positive relationship between sperm motility and mitochondrial enzyme-specific activities, suggesting that more specific mitochondrial dysfunction could be the underlying cause of idiopathic asthenozoospermia (Ruiz-Pesini et al., 1998). However, there was argument about whether ATP produced by the mitochondria can be effectively delivered from the mitochondria supply to entire flagellum (Nevo and Rikmenspoel, 1970; Adam and Wei, 1975)

As expected, in general such measurement led to variable results between laboratories or observers and the value of such measurement of motility in predicting fertility was still questionable due to the subjectivity of the technique. Subjective estimation of the sperm quality was affected by various causes; particularly variation in the observer's experience, the endpoints that are chosen and how these measures are interpreted (Rurangwa et al., 2004).

Sperm motility was one of the most important factors in determining the ability to produce viable sperms (Oyeyemi et al., 2000). True viability of spermatozoa was eventually defined by their capacity to move and fertilize an egg (Rurangwa et al., 2004). In this study, the viability of the sperm had been investigated by using Eosin-Nigrosin staining where the stain was based on the integrity of the sperm membrane. The ratio of the in vitro dead sperm cells was observed due to Eosin penetrating and staining the dead autolysing sperm cells while viable sperm repel the stain. In motility analysis, there were sperms that were graded with immotile as no movement, observed under the microscope. But, in certain condition, the immotile sperm were still viable. Therefore, in cases of low motility, viability analysis was carried out in order to confirm the status of sperm viability. MPAE was able to preserve the sperm viability as MPAE shows significant changes when compared to normal (negative control) for group IV. This might be due to Melicope ptelifolia having the potential in increasing the secretion of testosterone. Testosterone hormone is the principal of male reproductive hormones and play an important role in sperm quality (Parhizkar $e t$ al., 2013). Still, the mechanism on how sperm viability was maintained is still unknown (Smith and Nothnick, 1997).

The percentage of normal sperm morphology show significant increase for Group III, IV and V. The result indicated that MPAE treatment was able to maintain normal morphology of sperm as any sperm deformities was associated with functional deficiencies. This caused reduced motility and fertilization ability. Besides that, morphological sperm parameters were important for fertilization step meanwhile DNA integrity were crucial as it was related with the establishment and continuation of pregnancy (Tomlison et al., 2001). Apart from that, sperm morphology is the most informative semen measurement for discriminating between fertile and infertile male.

This present study concludes that the treatment with Melicope ptelifolia aqueous extract did produce a clear change in the sperm quality.

Table 1.5: Effect of MPAE on Testosterone level of the male rats

\begin{tabular}{llc}
\hline Groups & Description & Testosterone Level $(\mathbf{n g} / \mathbf{m L})$ \\
\hline I & Distilled Water & $2.7 \pm 0.23$ \\
II & $100 \mathrm{mg} / \mathrm{kg}$ & $4.10 \pm 0.22$ \\
III & $200 \mathrm{mg} / \mathrm{kg}$ & $6.68 \pm 0.38$ \\
IV & $500 \mathrm{mg} / \mathrm{kg}$ & $11.02 \pm 0.66 *$ \\
V & Sildenafil Citrate & $19.80 \pm 2.02 *$ \\
\hline & Each column represents the mean \pm S.E.M. of 6 rats.
\end{tabular}

The significant increased level of testosterone in $500 \mathrm{mg} / \mathrm{kg}$ group compared to control showed that testosterone has correlate with the increase of libido and sperm quality. The receptive female is believed to affect the activation of the hypothalamic-pituitary- testicular complex (HPTC) in the male which is indicated by the increased serum testosterone and luteinizing hormone levels (Bartke and Dalterio, 1975).

The excessive reactive oxygen species (ROS) generated by cell metabolism may suppress the ability of sperm function leading to infertility. ROS is physiologically generated during mitochondrial respiration in normal cell metabolism (de-Lamirande et al., 1997). The level of ROS reflects the highly specific lipid composition of sperm membrane cells as the main substrate for lipid peroxidation. At the low level of lipid peroxidation, where the ROS is low, the motility and functional ability of sperm cells to interact with zona pellucida will increase. However, the pathological lipid peroxidation of sperm membrane due to the high level of ROS will undergo unbalance oxidative stress in the testes (Aitken and Roman, 2008; Aitken et al., 1989). The presence of the intra and extracellular antioxidants of enzymatic and non-enzymatic system however will scavenge free radicals as self-protection mechanism (Alvarez et al., 1987). Intake of superoxide dismutase supplement was leading to the progressive sperm motility and improved the acrosome reaction (Griveau and Le Lannou, 1997). In this study, the administration of MPAE has succeeded in increasing the antioxidant enzyme activity of superoxide dismutase (SOD) and catalase (CAT) suggesting the MPAE has anti-oxidative effect that contribute to male fertility. 
As a conclusion, the profertility effect exerted by Melicope ptelifolia extracts bring about increases in sperm quality and plasma testosterone level in male Sprague-Dawley rats. The presence of saponin in Melicope ptelifolia might be the mechanism that trigger the aphrodisiac effect as shown however further study involving isolating and identifying the particular components of the plant that are responsible in conferring its profertility abilities could be useful in finding a remedy for infertility in male patients.

\subsection{Conflict of Interest}

The authors declare no conflict of interest.

\section{Acknowledgements}

The project was conducted from grants available from Universiti Putra Malaysia (Gran Putra 5524793) and Malaysian Ministry of Education-FRGS from Ministry of Higher Education.

\subsection{References}

Abas, F., Lajis, N.H., Israf, D.A., Khozirah, S., \& Kalsom, Y.U. Antioxidant and nitric oxide inhibition activities of selected Malay traditional vegetables. (2006). Food Chemistry, 95(4); 566-573. doi:10.1016/j.foodchem.2005.01.034

Ab. Karim, M.S., Nasouddin, S.S., Othman, M., Mohd Adzahan, N., Hussin, S.R. and Khozirah, S. Consumers' knowledge and perception towards Melicope ptelefolia (Daun Tenggek Burung): A preliminary qualitative study International Food Research Journal 18(4): 1481-1488 (2011)

Adam DE and Wei J (1975) Mass-transport of ATP within motile sperm. J Theor Biol 49,125-145.

Afendi Dahlan and Izzah Alia Mohamad Rosli. Formulation and Characterization of an Anti-Bacterial gel using tenggek burung (Melicope ptelefolia) J App Pharm Vol. 7; Issue 1: 83-95; January, 2015.

Aitken, R.J., Clarkson, J.S. \& Fishel, S. 1989. Generation of reactive oxygen species, lipid peroxidation, and human sperm function. Biology of Reproduction. 41: 183-197.

Aitken, R.J. \& Roman, S.D. 2008. Antioxidant systems and oxidative stress in the testes. Review of Oxidative Medicine and Cellular Longevity, $1(1): 15-24$

Alvarez, J.G., Touchstone, J.C., Blasco, L. \& Storey, B.T. 1987. Spontaneous lipid peroxidation and production of hydrogen peroxide and superoxide in human spermatozoa: superoxide dismutase as major enzyme protectant against oxygen toxicity. Journal of Andrology. 8: 338- 348.

Auger J, Jouannet P,. 1997. "Evidence for regional difference of semen quality among fertile French men." Hum Reprod 12: 740-745.

Bartke, A. \& Dalterio, S. 1975. Evidence for episodic secretion of testosterone in laboratory mice. Steroids. 26(6): 749-756.

Boyer, S.P., Davis, R.O., Katz, D.F., 1989. Automated semen analysis. Current problems in obstetrics. Gynecol. Fertil. 12, 165-200.

de-Lamirande, E., Jiang, H., Zini, A., Kodama, H. \& Gagnon, C. 1997. Reactive oxygen species and sperm physiology. Reviews of Reproduction. 2: 48-54.

Glade MJ and Smith K. Oxidative Stress, Nutritional Antioxidants, and Testosterone Secretion in Men. Ann Nutr Disord \& Ther. 2015;2(1): 1019.

Griveu, J.F. \& Le Lannou, D. 1997. Reactive oxygen species and human spermatozoa: physiology and pathology. International Journal of Andrology, 20(2): 61- 69. Motility and Protein Phosphorylation in Healthy and Asthenozoospermic Sperm.

Jana K, Samanta PK. Evaluation of single intratesticular injection of calcium chloride for nonsurgical sterilization in adult albino rats. Contraception Volume 73, Issue 3, March 2006, Pages 289-300

Hung PH, Miller MG, Meyers SA, VandeVoort CA (2008) Sperm mitochondrial integrity is not required for hyper- activated motility, zona binding, or acrosome reaction in the Rhesus Macaque. Biol Reprod 79: 367-375

Kamperdick, C. , Van, N. H. , Sung, T. V. , \& Adam, G. (1997).Phytochemistry, 45,1049.

Kamperdick, C. , Van, N. H. , Sung, T. V. , \& Adam, G. (1999).Phytochemistry, 50, 177-181.

Krause W. and Viethen, G. (1999) Quality assessment of computer-assisted semen analysis (CASA) in the andrology laboratory. Andrologia, $31,125-129$

Kulin HE, Reiter EO: Gonadotrophins during childhood and adolescence: a review. Pediatrics. 1973, 51: 260-271.

Loi DT. Nhung cay Thuoc va vi thuoc Viet Nam (Glossary of Vietnamese Medicinal Plants) Hanoi, Vietnam: Science and Technics Publication; 1977.

Mangelsdorf I, Buschmann J, Orthen B,. 2003. "Some aspects relating to the evaluation of the effects of chemicals on male infertility." Regul Toxicol Pharmacol 37: 356-369.

M. A. Rasadah and M. Zakaria, "Antibacterial activity of theextracts from Melicope and Euodia species," in Mala ysianTraditional Medicine, pp. 173-178, Kuala Lumpur, Malaysia,1988.

Nevo AC and Rikmenspoel R (1970) Diffusion of ATP in sperm flagella. J Theor Biol 26,11-18.

Nor-Raidah, R. and Mahanem, M.N. Enhancement of fertility and libido in male Sprague Dawley rats following the administration of aqueous extract Lunasia amara. Malays Appl Biol (2015) 44(I): 125-131

Oyeyemi MO, Akusu MO \& Ola-Davies, E.O, (2000). Effects of successive ejaculations on the spermiogram of West African Dwarf goats (Capra hircus L.). Veterinarski Arhiv. 70 (4), 215 - 221.

Parhizkar, Saadat \& Zairieha Binti Che Zainudin, Che \& Aziz Dollah, Mohammad. (2013). Effect of Phaleria macrocarpa on sexual function of rats. Avicenna Journal of Phytomedicine. 3. 371-377.

Perry LM, Metzger J. Medicinal Plants of South East Asia. Cambridge, UK: MIT Press; 1980. Attributed properties and uses.

Ruiz-Pesini E, Diez C, Lapena AC, Perez-Martos A, Montoya J, Alvarez E, Arenas J \& Lopez-Perez MJ. (1998) Correlation of sperm motility with mitochondrial enzymatic activities. Clin Chem 44, 1616-1620.

Rurangwa E., Kime D.E., Ollevier F., Nash J.P. 2004. The measurement of sperm motility and factors affecting sperm quality in cultured fish. Aquaculture 234(1- 4): 1-28

Shaari, K., Safri, S., Abas, F., Lajis, N., \& Israf, D. A. (2006). A geranylacetophenone from the leaves of Melicope ptelefolia. Natural Product Research, 20(5), 415-419. 
Shoji, N. Umeyama, A. , luchi, A., Saito, N. and Ariahara, S. 1989. Two novel alkaloids from Eudia rutaceacarpa. Journal of Natural Products 52: $1160-1162$.

Timothy Smith, T \& Nothnick, Warren. (1997). Role of direct contact between spermatozoa and oviductal epithelial cells in maintaining rabbit sperm viability. Biology of reproduction. 56. 83-9. 10.1095/biolreprod56.1.83.

T. J. David, "Rutaceae," in The Flora of Sabah and Sarawak, E. Soepadmo and K. M. Wong, Eds., Forestry Research Institute Malaysia, Kuala Lumpur, Malaysia, 1995.

Tomlinson M, Moffatt O, Manicardi GC, Bizzaro D, Afnan M and Sakkas D (2001) interrelationships between seminal parameters and sperm nuclear DNA damage before and after density gradient centrifugation: implications for assisted conception. Hum Reprod 16, 2160-2165.

World Health Organization. WHO Laboratory Manual for the Examination and Processing of Human Semen, 5thed. Geneva: WHO Press 2010. 